\title{
O PODER LEGISLATIVO MUNICIPAL PODE CONTRIBUIR PARA OS ODS: A EXPERIÊNCIA DE UM MANDATO DE VEREADOR EM BALNEÁRIO CAMBORIÚ
}

\author{
MEIRINHO, A. F. ${ }^{1 *} \&$ DACOL K. C. ${ }^{1}$ \\ 1. Programa de Pós-Graduação em Planejamento Territorial e Desenvolvimento Socioambiental, \\ Centro de Ciências Humanas e da Educação, Universidade do Estado de Santa Catarina \\ (UDESC) - Florianópolis, Santa Catarina, Brasil.
}

*Autor correspondente: afmeirinho@yahoo.com.br

\begin{abstract}
Meirinho, A. F. \& Dacol, K. C. (2020). The Municipal Legislative Power can Contribute to the SDGs: the experience of an alderman's term of office in Balneário Camboriú. Braz. J. Aquat. Sci. Technol. 24(1). elSSN 1983-9057. DOI: 16538/bjast.v24n1. The case brought to the roundtable entitled "SDGs and the Cities" comprises the initiatives in the environmental area related to the Sustainable Development Goals - SDGs, developed as city councilman in the chambre of councilors in the municipality of Balneário Camboriú. It is an innovative experience that used the objectives of the Sustainable Development Agenda, established by the United Nations. The proposals presented are linked with the triple bottom line: economic viability, social justice and respect for the environment. Such initiatives help to stimulate the city's resilience and improve citizens' quality of life.
\end{abstract}

Key Words: Sustainable Development Goals, Municipal Legislative Power, Balneário Camboriú.

\section{INTRODUÇÃO}

O caso, aqui apresentado, compreende as iniciativas na área ambiental relacionadas aos Objetivos de Desenvolvimento Sustentável-ODS, desenvolvidas no mandato no âmbito do Poder Legislativo do município de Balneário Camboriú. Trata-se de uma experiência inovadora que utilizou os objetivos da Agenda de Desenvolvimento Sustentável, estabelecida pelas Nações Unidas.

Os ODS constituem-se em 17 objetivos globais que se subdividem em 169 metas utilizadas para estruturar a Agenda 2030 que norteará as políticas públicas e a implementação de ações importantes para a humanidade e o planeta nos próximos anos. Foram estabelecidos pelas Nações Unidas como parte de uma nova agenda de desenvolvimento sustentável que visa dar continuidade ao trabalho dos Objetivos de Desenvolvimento do Milênio - ODM. Lançada em setembro de 2015 durante a Cúpula de Desenvolvimento Sustentável, a agenda foi firmada a partir da discussão na Assembleia Geral da ONU, onde os Estados-membros e a sociedade civil negociaram suas contribuições (ONU, 2015).

O Poder Legislativo Municipal é composto por um número de cadeiras de vereadores, com base no contingente populacional, conforme Lei Orgânica de cada município, respeitando o que dispõe o Art. 29 da Constituição Federal. O mandato de vereador tem duração de quatro anos e é estabelecido pelo voto direto, através do qual os eleitores conferem aos eleitos o poder de representatividade. Assim, os vereadores além de representarem a população no âmbito municipal, são responsáveis por fiscalizar as ações do Poder Executivo Municipal, atender às reivindicações da população e criar leis visando melhorar a qualidade de vida da população.

Devido à diversidade de demandas por políticas públicas e a complexidade dos problemas que os municípios enfrentam, raramente os vereadores conseguem atuar em todas as áreas. Assim, como linha de atuação alguns legisladores seguem as ideologias partidárias para orientar suas decisões, outros são mais atuantes na área da saúde, por exemplo, enquanto outros dedicam-se com maior ênfase à área social ou econômica, entre outras, conforme demandas da sociedade.

A experiência trazida aqui, portanto, apresenta uma inovação no mandato de vereador em curso no município de Balneário Camboriú, o qual faz valer o desenvolvimento sustentável como diretriz para a atuação no Poder Legislativo Municipal. Assim, as ações desenvolvidas e leis criadas vem sendo orientadas pelos ODS, visando o desenvolvimento sustentável e o alinhamento das políticas públicas locais com as políticas globais.

\section{O Município de Balneário Camboriú}

No caso do município de Balneário Camboriú, por se tratar de uma cidade litorânea, turística, com população estimada em 142.295 habitantes, área territorial limitada a $45,214 \mathrm{~km}^{2}$ e densidade demográfica 
de 2.337,67 hab/km², faz-se ainda mais necessário uma atuação focada na proposição de políticas públicas que busquem o equilíbrio entre os pilares econômico, social e ambiental, para que se possa buscar a manutenção da qualidade de vida que ainda é suportada por 0,845 de IDHM - Índices de Desenvolvimento Humano Municipal - IDHM, o quarto melhor do Brasil (IBGE, 2020).

Ao longo dos anos, a população de Balneário Camboriú cresceu de forma expressiva. Conforme dados populacionais levantados junto ao Instituto Brasileiro de Geografia - IBGE, a população passou de 10.839 habitantes fixos na década de 1970 para 21.851 na década de 1980 , de 40.308 no Censo do ano de 1991 para 73.455 no ano 2000, sendo que atualmente a população estimada já ultrapassa 140 mil habitantes (IBGE 2010 apud Dacol, 2013).

Conforme Leme (2010), antes da década de 1970, o Balneário era apenas uma praia de banho sem grandes aspirações de futuro, foi no governo de Gilberto Américo Meirinho (1973 -1977), gestão em que foram realizados os principais instrumentos de planejamento como Plano Viário, o Plano Diretor Físico Territorial, o Código de Normas e Instalações (antigo Código de Posturas), o Código de Obras e Edificações e o Código Tributário, visando o desenvolvimento equilibrado da cidade e como destino turístico. Foi na década de 1970 que a cidade recebeu os primeiros arruamentos com alargamento da Avenida Atlântica e Avenida do Estado, abertura da Terceira, Quarta e Quinta Avenidas, além dos primeiros projetos de saneamento básico, incluindo esgotamento sanitário e galerias pluviais. Estas ações do passado partiram de um prefeito visionário, que elevou a cidade como modelo nacional de planejamento turístico.

Alguns fatores serviram de gatilho para esse expressivo aumento populacional e expansão urbana da cidade de Balneário Camboriú: a construção da Rodovia BR-101 a partir da década de 1970, que ligou o Sul e o Norte do Brasil, o estímulo ao mercado da construção civil e a forte especulação imobiliária decorrentes, sobretudo, da valorização das belezas naturais e da Praia Central como alternativa de balneário, qualidade de vida e destino turístico internacional. Fatores que estimularam a priorização de investimentos em saneamento, em relação aos demais municípios do Estado de Santa Catarina, a partir da década de 1970, sendo o auge na implantação de infraestrutura de saneamento, compreendendo as primeiras grandes obras de rede coletora e estação de tratamento de esgoto na década de 1980 (Dacol, 2016).

Ao tratar da artificialização da paisagem, Piatto e Polette (2012) indicam que Balneário Camboriú, assim como o litoral catarinense, tem sido influenciado pelo processo de urbanização costeira, sendo um dos municípios afetados com essa transformação da paisagem a partir dos setores econômicos da construção civil, turismo e setor imobiliário, que levaram à verticalização e a um dos maiores índices de adensamento populacional no Estado de Santa Catarina, gerando artificialização da orla do município e impactos negativos em diferentes graus.

Diante desse cenário, é importante que as políticas públicas estejam voltadas ao desenvolvimento sustentável. Razão pela qual adotou se os ODS na orientação das proposições legislativas, de modo que contribua para buscar qualidade de vida.

\section{Mandato Legislativo com Foco no Desenvolvimento Sustentável em Balneário Camboríu}

A decisão de considerar os ODS como diretrizes do mandato de vereador, originou-se a partir do compromisso com o desenvolvimento sustentável. Além disto, o contexto que determinou o desenvolvimento territorial e a ocupação urbana no município de Balneário Camboriú e, sobretudo, as observações acerca da importância de políticas públicas que busquem uma visão holística e gestão por resultado, para melhor atender às necessidades da cidade e da população que busca garantir a qualidade de vida.

Para se buscar resultados na gestão pública é necessário ter objetivos e metas inter setoriais claras que considerem, no mínimo os seguintes aspectos: planejamento de cidade, vontade política, mandatos temporários, burocracia, foco e as diferentes visões que compõe um governo de diferentes partidos políticos, cabendo ao gestor articular os interesses diversos e fazer o governo caminhar de forma harmônica e na mesma direção (Meirinho, 2015).

\footnotetext{
"Assim com o norte da sustentabilidade, sua tradução em indicadores para que a gestão pública busque e efetivamente alcance os resultados necessários, tudo isso com questionamento, aperfeiçoamento e envolvimento de toda a sociedade é possível caminharmos em direção a uma melhor qualidade de vida e vida em harmonia." (Meirinho et al, , 2016, p.7).

Uma das formas utilizadas para buscar essa harmonia, buscando abranger as diferentes áreas de interesse local e global foi a adoção dos ODS como diretriz de mandato. Neste sentido, pautando-se nos 17 objetivos globais, apresenta-se no Quadro 1 uma síntese da atuação do vereador, incluindo os projetos de lei, atos legislativos e outras proposições, bem como os objetivos e resultados alcançados associando-os aos respectivos ODS.
} 
Quadro 1 - Síntese das proposições baseadas nos ODS apresentadas durante o mandato no município de Balneário Camboriú.

\begin{tabular}{|c|c|c|}
\hline Ato Legislativo & Objetivo principal/ Resultado & ODS \\
\hline Plano de Metas & $\begin{array}{l}\text { - Determina que o Prefeito eleito apresente um Plano de Metas até } 90 \text { dias após sua posse, além da divulgação dos resultados obtidos. O } \\
\text { objetivo é que a execução do Plano de Governo do Prefeito, suas ações estratégicas, indicadores, metas e resultados sejam divulgados } \\
\text { periodicamente para avaliação e participação da sociedade. Emenda à Lei Orgânica N.o 15/2017. }\end{array}$ & Todos \\
\hline Recursos Hídricos & $\begin{array}{l}\text { - Viabilizou apresentação na Câmara de Vereadores do Comitê da Bacia Hidrográfica do Rio Camboriú e Contíguas sobre o Parque Inundável, } \\
\text { iniciativa que visa reserva de água bruta e contenção de cheias; } \\
\text { Emenda no Plano Plurianual a fim de garantir dotação orçamentária denominada Produtor de Águas. Emenda no } 4 \text { ao PL no 140/2017; } \\
\text { - Questionou sobre o Pacto das Águas; outorga de uso da água do Rio Camboriú e captação do rio Itajaí-Mirim. Pedido de Informação no } \\
\text { 79/2019; } \\
\text { - Indicou estudo de viabilidade para o tratamento da água de abastecimento público com ozônio. Indicação no 1184/2019; } \\
\text { - Projeto de lei que “Institui a Política Municipal de Segurança Hídrica e Desenvolvimento Sustentável”. Projeto de Lei no 226/2019. }\end{array}$ & $\begin{array}{l}03 ; 06 ; 11 ; 12 ; 14 ; \\
17\end{array}$ \\
\hline $\begin{array}{l}\text { Incentivo à inovação, } \\
\text { tecnologia e cidade } \\
\text { inteligente }\end{array}$ & $\begin{array}{l}\text { - Incentivar a economia com a criação de ecossistemas de empreendedorismo e inovação objetivando reunir investidores, startups, } \\
\text { instituições acadêmicas, empresas de tecnologia e poder público, visando ambientes colaborativos que gerem soluções sustentáveis e } \\
\text { aproximem o município do conceito de cidade inteligente (smart city). Projeto de Lei } \mathbf{n} \mathbf{0} 6 \mathbf{6 6} \mathbf{2 0 1 9} \text {. }\end{array}$ & $\begin{array}{l}03 ; 04 ; 06 ; 07 ; 08 ; \\
09 ; 10 ; 11 ; 12 ; 16 ; \\
17\end{array}$ \\
\hline $\begin{array}{l}\text { Regulamentação dos } \\
\text { Parklets }\end{array}$ & $\begin{array}{l}\text { - Valorizar o pedestre, tornando algumas vagas de estacionamento em espaços de convivência. Semelhantes a miniparques, estes espaços } \\
\text { ocupam vagas de estacionamento em vias públicas pré-definidas, contemplando floreiras, bancos, mesas, lixeiras, paraciclos, entre outros. Lei } \\
\text { Municipal } \mathbf{n} \mathbf{0} \mathbf{4 . 2 4 6} \text {, de } \mathbf{0 8} \text { de março de } \mathbf{2 0 1 9} \text {. }\end{array}$ & $03 ; 11 ; 17$ \\
\hline $\begin{array}{c}\text { Pontos de coleta de óleo } \\
\text { de cozinha }\end{array}$ & $\begin{array}{l}\text { - Determinar que os supermercados, com área superior a } 800 \mathrm{~m}^{2} \text {, recolham óleo de cozinha usado. Lei Municipal no 4.034, de 19 de maio de } \\
2017 \text {. }\end{array}$ & $06 ; 12 ; 13 ; 14 ; 15$ \\
\hline $\begin{array}{l}\text { Preservação da Praia de } \\
\text { Taquarinhas }\end{array}$ & $\begin{array}{l}\text { - Indicar Decreto de Utilidade Pública, com a finalidade de criação de uma Unidade de Conservação municipal, atendida pelo Prefeito. Apoio } \\
\text { ao movimento Pró-Taquarinhas. Encaminhamento de moção de apelo à ALESC. Retirado item "Praia de Taquarinhas" do leilão e viabilização de } \\
\text { reunião com a Caixa Econômica Federal - CEF com apoio do Senador Esperidião Amin. Indicações no 213/2016, 417/2017, 634/2019 e } \\
\text { 744/2019, Requerimento no 06/2016 e Moções no 285/2017 no 13/2019. }\end{array}$ & $\begin{array}{l}03 ; 04 ; 06 ; 11 ; 13 ; \\
14 ; 15 ; 16 ; 17\end{array}$ \\
\hline Fiscalização no legislativo & $\begin{array}{l}\text { - Fiscalizar o Programa Produtor de Água; } \\
\text { - Fiscalizar o Programa Se Liga na Rede e apresentação do Projeto de Lei do Selo Se Liga na Rede Projeto de Lei no 150/2019; } \\
\text { - Audiência Pública sobre resíduos sólidos. }\end{array}$ & $\begin{array}{c}03 ; 04 ; 06 ; 11 ; 12 ; \\
14\end{array}$ \\
\hline $\begin{array}{l}\text { Conselho Municipal de } \\
\text { Relações Internacionais e } \\
\text { Federativas }\end{array}$ & $\begin{array}{l}\text { - Criar o conselho, que tem como principal atribuição o apoio técnico aos órgãos do município, através de assessoria direta, no } \\
\text { relacionamento com entidades governamentais e não governamentais internas e externas, mais especificamente na cooperação com a União, } \\
\text { Estados, Municípios, bem como entes e organizações de outros países. Lei Municipal no } \mathbf{4 1 2 1} \text {, de } \mathbf{2 6} \text { de abril de } \mathbf{2 0 1 8 .}\end{array}$ & $11 ; 17$ \\
\hline Estatuto do Pedestre & $\begin{array}{l}\text { - Garantir segurança, acessibilidade e conforto para a mobilidade a pé. A proposta visa ter o pedestre como elemento central nas políticas de } \\
\text { mobilidade, por meio da melhoria da qualificação e de garantir direitos e deveres ao pedestre, que permita ter segurança, mobilidade, } \\
\text { acessibilidade e conforto nos deslocamentos no município. Projeto de Lei Substitutivo no } \mathbf{1} \text { ao Projeto de Lei no } \mathbf{1 4 1 / 2 0 1 7} \text {. }\end{array}$ & $03 ; 09 ; 11$ \\
\hline $\begin{array}{c}\text { Proposituras relacionadas } \\
\text { à Pandemia do novo } \\
\text { coronavírus, causador da } \\
\text { covid -19 }\end{array}$ & $\begin{array}{l}\text { - Dispor sobre a proibição do corte do fornecimento dos serviços públicos de água e esgoto, por falta de pagamento, no período que } \\
\text { especifica em razão da Pandemia do Novo Coronavírus, causador da COVID - 19. Projeto de Lei no 29/2020; } \\
\text { - Indicação no 740/2020 - Realização de estudo técnico para constituição de um PACOTE DE APOIO AOS EMPREENDEDORES MUNICIPAIS, } \\
\text { visando medidas de apoio para combater os prejuízos econômicos decorrentes da paralisação de suas atividades em razão da Pandemia do } \\
\text { Novo Coronavírus causador da COVID 19, a fim de garantir a manutenção de suas atividades e de seus vínculos empregatícios; } \\
\text { - Indicação no 742/2020 - Higienização e desinfecção de vias e áreas públicas do município de Balneário Camboriú, através da aplicação de } \\
\text { sanitizante como hipoclorito de sódio entre outros que tenham potencial de combater fungos, bactérias e vírus, como o Coronavírus, } \\
\text { causador da COVID-19, sem prejuízo ao meio ambiente; } \\
\text { - Indicação no 759/2020 e Moção de Apelo no } \mathbf{8 2 / 2 0 2 0 ~ a o ~ G o v e m a d o r ~ - ~ V i a b i l i z a r ~ a ~ a b e r t u r a ~ d o ~ H o s p i t a l ~ S a n t a ~ I n e ̂ s , ~ b e m ~ c o m o ~ a t r a v e ́ s ~ d e ~} \\
\text { parcerias com iniciativa privada, complementando a estrutura já existente com os equipamentos necessários e equipe técnica, a fim de } \\
\text { garantir mais leitos de internação hospitalar para atendimento à demanda do município durante a Pandemia do Novo Coronavírus; } \\
\text { - Indicação no 836/2020 - À Empresa Municipal de Água e Saneamento de Balneário Camboriú - EMASA, para que forneça água emergencial } \\
\text { por caminhão pipa, no período declarado como Estado de Calamidade Pública decorrente do Novo Coronavírus (COVID-19), nas comunidades } \\
\text { que não são atendidas por rede pública de abastecimento de água; } \\
\text { - Indicação no 784/2020 - Promover orientação à população e o manejo adequado dos resíduos domiciliares classificados como Resíduos de } \\
\text { Serviços de Saúde COVID19 (RSS-COVID-19), gerados no local utilizado para isolamento/quarentena de pessoas com diagnóstico de caso } \\
\text { suspeito ou confirmado de COVID-19. }\end{array}$ & $03 ; 06 ; 08$ \\
\hline
\end{tabular}

\section{CONCLUSÃO}

Tendo como pressuposto que a ocupação do solo é regulada pelo Poder Público, incluindo o Poder Executivo e a atuação do Poder Legislativo na aprovação de leis, os dados populacionais apresentados pelo IBGE indicam a hipótese de que o crescimento populacional foi de certo modo estimulado pelas políticas públicas. Neste sentido, os poderes legislativos municipais, logo os mandatos de vereadores, também têm a sua parcela de importância no desenvolvimento de cidades mais sustentáveis.

Com base nesta experiência, acredita-se que o mandato legislativo de vereador em qualquer município deveria se valer dos princípios de desenvolvimento sustentável, por ser o mais ponderável modelo que tem orientado as nações na busca de um desenvolvimento harmônico, que atenda as necessidades humanas das atuais e das futuras gerações.

As proposições apresentadas vão ao encontro do tripé da sustentabilidade: viabilidade econômica, justiça social e respeito ao meio ambiente. Tais iniciativas contribuem para estimular a capacidade de resiliência da cidade e melhorar a qualidade de vida dos cidadãos.

\section{REFERÊNCIAS}

BALNEÁRIO CAMBORIÚ. Emenda à Lei Orgânica $n^{\circ}$ 15/2017. Modifica e acrescenta dispositivos à Lei Orgânica Municipal, nos termos da Constituição da República Federativa do Brasil e do Estado de 
Santa Catarina. Disponível em: http://leismunicipa. is/nlqvr. Acesso em: 10 de jun. 2020.

Lei municipal $n^{\circ} 4.034$, de 19 de maio de

2017. Dispõe sobre a criação em supermercados de pontos coletores de óleo vegetal usado, e dá outras providências. Disponível em: http:// leismunicipa.is/pmqvj. Acesso em 08 jun. 2020.

Lei municipal $n^{\circ} 4.121$, de 26 de abril de 2018.

Dispõe sobre a criação do Conselho Municipal de

Relações Internacionais e Federativas - CMRIF.

Disponível em: http://leismunicipa.is/wfgbk. Acesso em: 08 de jun. de 2020.

Lei municipal $n^{\circ} 4.246$, de 08 de maro

de 2019. Regulamenta a instalação e utilização de extensão móvel temporária de passeio público, através de plataformas com mobiliários urbanos, denominado PARKLETS, e dá outras providências." Disponível em: http://leismunicipa. is/odpnx. Acesso em 08 jun. 2020.

CÂMARA DE VEREADORES DE BALNEÁRIO CAMBORIÚ. Projeto de Lei $n^{\circ} 66 / 2019$. Vereador André Meirinho. Dispõe sobre incentivos à inovação e à pesquisa científica e tecnológica, criação do Conselho Municipal de Inovação, objetivando ambientes produtivos e Cidade Inteligente (Smart City) e dá outras providências no âmbito do município de Balneário Camboriú, conforme o disposto na Lei Federal $n^{\circ} 10.973$, de 2 de dezembro de 2004 e suas alterações. Disponível em: https://www.balneariocamboriu.sc.leg.br/ camara/proposicao/Projetos-de-Leis-ordinarias/ 0/1/0/109511. Acesso em: 08 de jun. 2020.

Projeto de lei substitutivo $\mathrm{n}^{\circ} 1$ ao projeto de lei $n^{\circ} 141 / 2017$. Vereador André Meirinho. Institui o estatuto do pedestre no município de Balneário Camboriú e dá outras providências. Disponível em: https://www.balneariocamboriu.sc.leg.br/camara/ proposicao/Projetos-de-Leis-Substitutivos /0/1/0/112529. Acesso em: 08 de jun. de 2020.

. Projeto de Lei no 150/2019. Vereador André

Meirinho. Institui o selo "Se Liga na Rede" e da outras providências. Disponível em: https://www.balneario camboriu.sc.leg.br/camara/proposicao/Projetosde-Leis-ordinarias/0/1/0/111233. Acesso em: 10 de jun. 2020.

. Projeto de Lei $n^{\circ} 226 / 2019$. Vereador André Meirinho. Institui a Política Municipal de Segurança Hídrica e Desenvolvimento Sustentável. Disponível em: https://www.balneariocamboriu.sc.leg.br/ camara/proposicao/Projetos-de-Leis-ordinarias/ 0/1/0/112469. Acesso em: 08 de jun. 2020.

Projeto de Lei $n^{\circ}$ 29/2020. Vereador André Meirinho et al. Dispõe sobre a proibição do corte do fornecimento dos serviços públicos de água e esgoto, por falta de pagamento, no período que especifica em razão da pandemia do novo coronavírus, causador da COVID-19. Disponívelem https://www.balneariocamboriu.sc.leg.br/ camara/proposicao/Projetos-de-Leis-ordinarias /0/1/0/113872. Acesso em: 08 de jun. 2020.

. Pedido de Informação n 79/2019. Disponível

em: https://www.balneariocamboriu.sc.leg.br/ camara/proposicao/Pedidos-de-Informacoes /0/1/0/109960. Acesso em: 08 jun. 2019.

Requerimento $n^{\circ} 06 / 2016$. Disponível em:

https://www.balneariocamboriu.sc.leg.br/camara/ proposicao/Requerimentos/2020/1/0. Acesso em: 10 jun. 2020.

Moções n 285/2017 e 13/2019. Disponível em: https://www.balneariocamboriu.sc.leg.br/ camara/proposicao/Mocoes/2020/1/0. Acesso em: 10 jun. 2020

Indicações. Disponível em: https://www. balneariocamboriu.sc.leg.br/camara/proposicao/ Indicacoes/2020/1/0. Acesso em: 08 jun. 2020

DACOL, K. C. O Desenvolvimento do sistema de esgotamento sanitário em Balneário Camboriú SC à luz das políticas públicas. $102 \mathrm{f}$. Dissertação (Mestrado em Planejamento Territorial e Desenvolvimento Socioambiental) - Centro de Ciências Humanas e da Educação, Universidade do Estado de Santa Catarina, Florianópolis, 2013. Disponível em:http://www.faed.udesc.br/arquivos/ id_submenu/872/kelli_cristina_dacol.pdf. Acesso em: 29 maio 2020.

. Políticas públicas de saneamento em mapas temáticos: O Desenvolvimento do sistema de esgotamento sanitário em Balneário Camboriú - SC. Saabrücken: Novas Edições Acadêmicas, 2016

LEME, P. O semeador - vida e obra de um vencedor. Biografia política de Gilberto Américo Meirinho. Balneário Camboriú/ SC: Taqui, 2010.

MEIRINHO, A. F. Santa Catarina e os megaeventos esportivos: um estudo a partir da paradiplomacia. Dissertação (Mestrado) Programa de PósGraduação em Planejamento Territorial e Desenvolvimento Socioambiental, 178p. Universidade do Estado de Santa Catarina, Florianópolis, 2015. Disponível em: http://www. faed.udesc.br/arquivos/id_submenu/1962/andre_ furlan_meirinho.pdf. Acesso em: 10 jun. 2016.

. Santa Catarina e os megaeventos esportivos: um estudo a partir da paradiplomacia. Saarbrücken: Novas Edições Acadêmicas, 2015.

MEIRINHO, A. F.; BUCIOR, E. R.; DIAS, V. L. N. Gestão pública para resultados e indicadores de desenvolvimento sustentável. Para onde!?, Porto Alegre, v. 8, ed. 2, p. 114-122, 13 jan. 2016. DOI https://doi.org/10.22456/1982-0003.61584. Disponível em: https://seer.ufrgs.br/paraonde/ 
article/view/61584/36416. Acesso em: 29 maio 2020.

ONU. Pos 2015. 2015. Disponível em: <https:// nacoesunidas.org/pos2015/. Acesso em: mai.2020.

PIATTO, L.; POLETTE, M. Análise do processo de artificialização do município de Balneário Camboriú, SC, Brasil. Revista da gestão costeira integrada, Itajaí, v. 12, ed. 1, p. 77-88, 24 fev. 2012. Disponível em: http://www.scielo.mec.pt/pdf/rgci/ v12n1/v12n1a07.pdf. Acesso em: 29 maio 2020. 